\title{
Inclusão Social e Acesso às Universidades Públicas: o Programa "Professores do Terceiro Milênio"
}

\author{
SIMÃO DIAS VASCONCELOS ${ }^{1}$ \\ $\mathrm{PhD}$ em Zoologia pela University of Oxford \\ Professor Adjunto da Universidade Federal de Pernambuco - UFPE \\ Coordenador do Laboratório de Ensino de Zoologia do Centro de Ciências \\ Biológicas da UFPE \\ simao@ufpe.br \\ KÊNIO ERITHON CAVALCANTE LIMA \\ Licenciado em Ciências Biológicas pela UFPE \\ simao@ufpe.br
}

\begin{abstract}
Resumo
A enorme desigualdade de acesso ao ensino superior entre estudantes de escolas públicas e privadas estimula a criação de estratégias para ampliar a "competitividade" dos egressos da rede pública. O Programa Professores do Terceiro Milênio, desenvolvido conjuntamente pela Universidade Federal de Pernambuco e Universidade Federal Rural de Pernambuco, visa oferecer formação complementar a estudantes de escolas públicas. Prioriza os cursos de Licenciatura em Ciências da UFPE e UFRPE, pois almeja, a médio prazo, a formação de professores com domínio do conhecimento científico e compromisso com a qualidade da educação do país. O curso é diário e gratuito, e as aulas são ministradas por alunos de licenciaturas. Desde 1997, o curso já aprovou 420 alunos de cursos de Licenciaturas em Ciências das universidades federais, com índices médios de aprovação variando entre $24 \%$ e $66 \%$. A área de Biologia vem sendo a mais procurada, e com maior taxa de aprovação. $\mathrm{O}$ Programa é, atualmente, um dos maiores deste modelo no país e contribui para que estudantes carentes aumentem seu potencial para aprovação em cursos de alto nível, ampliando seu direito à cidadania.

Palavras-chave: ensino de ciências, cidadania, educação superior, inclusão social.
\end{abstract}

\section{Resumen}

La gran desigualdad de acceso a la enseñanza superior entre estudiantes de escuelas públicas y privadas estimula la creación de estrategias para ampliar la "competitividad" de los que provienen de escuelas públicas. El Programa Profesores del Tercer Milenio, desarrollado en conjunto por la Universidade Federal de Pernambuco y por la Universidade

1 Os autores agradecem aos alunos, professores, monitores e supervisores do Programa Professores do Terceiro Milênio, em especial ao Dr. Manoel Lemos, Sra. Rosângela Casé e à FACEPE, por tornar disponível parte das informações. 
Federal Rural de Pernambuco, con vistas a ofrecer educación complementaria a estudiantes de escuelas públicas. Prioriza los cursos de Profesorado en Ciencias de la UFPE y UFRPE, pues pretende, a medio plazo, la formación de profesores con dominio del conocimiento científico y compromiso con la calidad de la educación en el país. El curso es diario y gratuito, y las clases son dadas por alumnos de la licenciatura. Desde 1997, el curso ha aprobado 420 alumnos de los cursos de Licenciatura en Ciencias de las universidades federales, cuyos índices medios de aprobación han variado entre $24 \%$ y $66 \%$. El área de Biología sigue teniendo la mayor demanda, con la mayor tasa de aprobación. El programa es, actualmente, uno de los mayores que siguen este modelo en el país y contribuye para que estudiantes carecientes aumenten su potencial de aprobación en cursos de nivel superior, ampliando sus derechos a la ciudadanía.

Palabras-clave: enseñanza de las Ciencias, ciudadanía, universidad, inclusión social.

\begin{abstract}
The enormous inequity in the access to university among students from private and public schools fosters the creation of strategies aiming to increase the "competitiveness" of students from public schools. The Program Teachers of the Third Millennium, developed by the Universidade Federal de Pernambuco (UFPE) and the Universidade Federal Rural de Pernambuco (UFRPE), aims to offer continued education to students from public schools. It envisages mainly candidates to Science Teaching Courses at UFPE and UFRPE, as it seeks to turn out teachers with a thorough scientific knowledge and a strong commitment with the quality of education in Brazil. The classes, taught by students of Science Teaching Courses, are daily and free. Since 1997, the Program has helped to approve 420 students at the public universities with approval rates ranging from $24 \%$ to $66 \%$. Biology is the most sought after area, and the one with the highest approval rates. The Program is one of the largest of its kind in Brazil and it helps empowering less-privileged students to join higher education, amplifying their access to full citizenship.
\end{abstract}

Key words: Science teaching, citizenship, undergraduate courses, social inclusion. 


\section{INTRODUÇÃO}

\section{Universidade brasileira: acesso para todos?}

O desafio para ingressar em um curso superior, em especial nas universidades públicas, torna a seleção de candidatos um processo predominantemente elitista e o acesso a elas é limitado para estudantes provenientes de escolas da rede pública. A competição por uma vaga nas universidades é incrementada pelas crescentes exigências de especialização do mercado de trabalho e pelo aumento significativo no número de alunos que concluíram o ensino médio nos últimos anos. Há cerca de 8,4 milhões de alunos regularmente matriculados no ensino médio no Brasil, sendo 7,3 milhões matriculados em escolas públicas e cerca de 1,1 milhão em escolas particulares (Inep, 2001), dos quais uma expressiva proporção, naturalmente, possui intenção (mas não necessariamente condições) de ingressar no ensino superior. Considerando que anualmente são abertas cerca de 230 mil vagas em instituições de ensino superior públicas (Inep, 2001), é natural que ocorra um processo de seleção cujo resultado, longe de representar a proporção "típica" do estudante brasileiro, reflete iniqüidades no processo de formação básica do aluno.

Sabe-se que a qualidade do ensino médio nas escolas públicas brasileiras apresenta-se comprometido, devido a obstáculos de natureza diversa e altamente complexa. Entre eles, destacam-se deficiências de infra-estrutura e no material de apoio didático, precária segurança nas escolas, insuficiente motivação discente e docente - originada em parte pela adoção de práticas pedagógicas inadequadas, péssima remuneração dos professores e a desatualização docente diante das novas metodologias e tecnologias de ensino. Tantos problemas reduzem a "competitividade" do aluno proveniente de escola pública em comparação a seu colega de escola particular. Como ressalta Castro (2001),

“... a extrema fragilidade do nosso primário e secundário faz com que as classes sociais sejam peneiradas e que as mais pobres estejam extraordinariamente subrepresentadas no nível superior. Isso não é culpa do ensino superior. Ele apenas herda a iniqüidade dos níveis mais baixos de educação." (p.120)

Alguns agravantes aprofundam a exclusão do aluno oriundo de escola pública no ensino superior. Ortega (2001) destaca a falta de perspectiva inserida na educação do aluno de nível médio:

“...podemos perceber que enquanto a escola particular de elite tenta preparar seu aluno para o ingresso numa boa universidade pública, a escola pública não 
apresenta nenhuma orientação específica neste sentido, colaborando, muito provavelmente sem saber, para que esses alunos não cheguem mesmo a tentar o ingresso no ensino superior. Consideramos que isto pode fazer com que os alunos da escola pública de ensino médio se sintam cada vez mais desmotivados, inseguros e despreparados para viver na sociedade contemporânea, que além de exigir um nível maior de escolaridade, apresenta um contexto preocupante, principalmente para quem não tem uma boa formação geral." (p.154)

Considerando-se que a garantia plena da cidadania deve incluir a igualdade de acesso à educação em todos os níveis, é essencial que se corrijam desigualdades no acesso ao ensino universitário no país. É evidente o elevado grau de elitismo da universidade brasileira, o que acaba por distanciá-la das grandes questões sociais. Grupos tradicionalmente caracterizados como "minorias", tais como negros, índios, portadores de deficiência física e alunos de escolas públicas, entre outros, têm sido absurdamente sub-representados no ensino superior.

Nos últimos anos, tem se debatido sobre o sistema de cotas para beneficiar tais minorias. Neste sentido, as universidades estaduais saíram na frente: por exemplo, A Lei Estadual 3.524/2000 reserva 50\% das vagas da graduação na Universidade Estadual do Rio de Janeiro (UERJ) e da Universidade Estadual do Norte Fluminense (UNENF) para candidatos que estudaram em escolas públicas do estado. A Lei 3.708/2002, por sua vez, reserva $40 \%$ das vagas das referidas instituições para candidatos negros e pardos. Em 2003, a Universidade de Brasília decidiu reservar 20\% de suas vagas para afrodescendentes.

\section{Alternativas para o sistema de cotas}

A questão da obrigatoriedade de cotas tem suscitado um ardente - e justificado - debate. Há problemas óbvios resultantes da adoção de cotas: em primeiro lugar, há a dificuldade de se estabelecer objetivamente o critério de raça e cor (bastante discutível, até do ponto de vista genético). Em segundo lugar, muitos candidatos podem se declarar negros ou pardos apenas para se beneficiar das cotas, gerando um sentimento de injustiça nos candidatos "brancos" que, mesmo alcançando índice satisfatório, podem acabar não ingressando na universidade.

"Enquanto a polêmica sócio-jurídica em torno dessas questões reaviva as relações de raça e poder na sociedade, juristas, cientistas políticos e representantes da sociedade civil as analisam com mais acuidade, buscando o equilíbrio entre a necessidade de relocar bens e direitos aos excluídos, e o polêmico caminho de sua aquisição imediata apresentado pelas ações afirmativas." (César, 2003, p. 27) 
Adicionalmente, os opositores ao sistema de cotas argumentam que tal medida pode permitir a entrada de pessoas com deficiências de formação obtida nos ensinos fundamental e médio, o que pode acarretar a reprovação em massa desses estudantes na universidade. Isso pode gerar, a médio prazo, perda da qualidade dos cursos e, até mesmo, a perpetuação do preconceito por parte do mercado de trabalho, já que o futuro profissional carregará o "estigma" de ter ingressado na universidade graças a programas de ação afirmativa.

As ações afirmativas, como tentativa de minimizar o cruel desnível na participação de grupos mais vulneráveis à discriminação na sociedade, são iniciativas profícuas e, quando bem planejadas, altamente eficientes. Entretanto, acreditamos que, em uma área complexa tal como a educação, para reduzir as diferenças nos níveis de conhecimento e no desenvolvimento de habilidades, as iniciativas não podem ter caráter pontual, mas devem começar e conservar-se por período suficiente para produzir mudanças antes do ingresso nas universidades.

"A falta de igualdade de oportunidades se dá onde o sistema penaliza o acesso por razões que não têm nada a ver com diferenças de mérito ou desempenho usualmente pobreza e distância das escolas. Mas igualdade de oportunidade não pode ser considerada na véspera de entrar no ensino superior, quando todas as forças centrifugas que separam as experiências educativas dos ricos e dos pobres já exerceram seu papel devastador. Não há igualdade de oportunidades quando o sistema nada faz para evitar o aparecimento de grandes diferenças que, por sua vez, vão determinar as enormes diferenciações no acesso a níveis subseqüentes ou ao mercado." (Castro, 2001, p. 110)

Como enfrentar, então, as críticas de que "igualdade forçada no exame vestibular" não representa a forma mais equilibrada de garantir a "competitividade" do aluno marginalizado? Uma estratégia de custo relativamente baixo e de resposta eficiente a curto prazo consiste no estabelecimento de programas de consolidação de conhecimento que permitam aprofundar o conteúdo trabalhado no ensino médio e aumentar a chance do candidato enfrentar o exame vestibular em melhores condições de aprovação. Tais programas podem assumir o formato de cursos prévestibulares gratuitos destinados a populações tradicionalmente excluídas do ensino superior.

Recentemente, tem-se observado o surgimento de projetos destinados a promover o acesso mais democrático de parcelas menos favorecidas da população às universidades públicas. Por exemplo, na Universidade Federal Fluminense, alunos de escolas públicas recebem formação complementar através do envolvimento de estudantes dos cursos 
de licenciatura daquela instituição (Andrade et al., 2002). Em Pernambuco, existe o Programa "Rumo à Universidade", uma parceria entre universidades públicas locais e a Secretaria de Educação do Estado, que promove aulas nos finais de semana para alunos de baixa renda, os quais recebem uma bolsa-auxílio. Observa-se um crescimento de cursos prévestibulares destinados a populações "marginalizadas", havendo iniciativas deste curso nas universidades federais de Alagoas, Rio de Janeiro, Minas Gerais, São Paulo, Bahia e Pernambuco.

Embora nos últimos anos programas de apoio à formação complementar do candidato ao ensino superior tenham sido criados, as universidades brasileiras desenvolvem ainda poucas iniciativas duradouras neste sentido. Projetos de extensão são escassos, com limitado envolvimento de estudantes de Licenciatura, e nem sempre mantêm a necessária continuidade para garantir resultados de impacto social. $\mathrm{Na}$ Universidade Federal de Pernambuco, destaca-se um programa de extensão que tem contribuído para encurtar a distância ente a escola pública e a universidade, o "Programa de Formação de Formadores para o Ensino Médio: Professores do Terceiro Milênio".

\section{O PROGRAMA “PROFESSORES DO TERCEIRO MILÊNIO”}

\section{CARACTERIZAÇÃo do Programa}

\section{Objetivos}

O "Programa de Formação de Formadores para o Ensino Médio: Professores do Terceiro Milênio", conhecido como Programa "Professores do Terceiro Milênio", é desenvolvido pela Universidade Federal de Pernambuco (UFPE) e pela Universidade Federal Rural de Pernambuco (UFRPE). Visa a oferecer a alunos de baixa renda a oportunidade de adquirir e aprofundar seus conhecimentos nas disciplinas de Matemática, Física, Química, Biologia, Português, Geografia, História e Língua Estrangeira. Objetiva, desta forma, amplificar a competitividade de alunos oriundos de escolas públicas por uma vaga nas universidades federais em relação a alunos provenientes de colégios particulares e cursinhos prévestibulares. Ao mesmo tempo, busca complementar eventuais deficiências de formação de conteúdos, para que o estudante ingresse na universidade com uma base mais sólida dos tópicos abordados no ensino médio. 
Os alunos do projeto devem almejar um dos seguintes cursos de Licenciatura oferecidos pelas universidades federais locais: Ciências Biológicas, Computação, Física, Matemática ou Química. O programa não visa a apenas aumentar a aprovação de alunos de escolas públicas mas pretende-se a médio prazo formar professores dotados de profundo conhecimento científico associado à consciência dos problemas educacionais e ao compromisso de buscar soluções adequadas a sua realidade.

\section{Por que Licenciaturas em Ciências?}

A expansão do ensino fundamental e médio no Brasil ocorrida nos últimos anos tem promovido significativa queda nos índices de analfabetismo, e aumentado a escolaridade média do estudante brasileiro. Entretanto, tal expansão não veio acompanhada de uma renovação suficiente no quadro de professores das escolas públicas. Há em todo o país uma enorme carência de professores, em particular de Ciências. Considerando-se o desempenho pífio dos estudantes brasileiros em avaliações internacionais de Ciências (PISA, 2000), percebe-se que a formação de professores de Ciências tem falhado no processo de alfabetização científica dos nossos alunos.

A formação de professores tem papel crucial, e, sem dúvida, é uma das mais importantes dentre as políticas públicas para a educação, pois os atuais desafios escolares exigem do educador outro patamar profissional, muito superior ao hoje existente (Laranjeira et al., 1999, p. 21). Os cursos de Licenciatura parecem sofrer de uma "crise de identidade" nas instituições e por parte dos próprios alunos. São, com raras exceções, considerados cursos menores, nos quais há grotesca divisão entre as disciplinas de conteúdo "específico" e as de conteúdo "pedagógico". Grande parte dos alunos desconhece as potencialidades do mercado de trabalho e sua área de atuação, principalmente a pesquisa em educação, raramente estimulada nesses cursos (Vasconcelos, 2000). Tais deficiências justificam a formação de programas destinados a repensar o papel das licenciaturas e seu comprometimento com as transformações na educação brasileira.

Um fator a ser considerado é a necessidade de estimular os cursos noturnos em universidades públicas. O horário noturno é comumente subaproveitado em muitas instituições, e, em alguns casos, há até mesmo resistência de professores em ministrar aulas nesse horário. Na UFPE, as licenciaturas são tradicionalmente oferecidas no horário noturno. Enquanto durante o dia a quantidade e o porte das salas e laboratórios são 
insuficientes para atender à demanda dos cursos oferecidos, com competição por espaço e equipamentos, à noite as instalações chegam a ser sub-utilizadas.

\section{Operacionalização do Programa}

O programa é uma parceria entre as universidades federais de Pernambuco e o Ministério da Educação, com apoio do Governo do Estado de Pernambuco. Foi oficialmente iniciado em 1997, e desde então vem sendo aperfeiçoado, a fim de ampliar seu público-alvo, as áreas beneficiadas e as instituições envolvidas. Em seus primeiros anos, teve o apoio da Secretaria de Ciência, Tecnologia e Meio Ambiente (através da Fundação de Amparo à Ciência e Tecnologia do Estado de Pernambuco) e da Secretaria de Educação de Pernambuco. Em 2003, os recursos foram provenientes da Secretaria de Educação Superior do Ministério da Educação, num montante de R\$ 108 mil reais (ca. U\$ 36 mil), administrados pela Fundação de Apoio ao Desenvolvimento da Universidade Federal de Pernambuco (FADE). As verbas cobrem despesas com material, serviços, fotocópias, e, principalmente, bolsas para os instrutores do programa.

O programa inicia-se com a divulgação pública em jornais e emissoras de rádio. O candidato deve estar cursando o $3^{\circ}$ ano do ensino médio ou tê-lo concluído em escola pública nos últimos cinco anos e ter interesse em cursos de Licenciatura. Em 2002, foram inscritos cerca de 2.000 candidatos, dos quais foram selecionados 600 por meio de um teste de qualificação de Matemática e Português. Tais alunos seguiram para um curso de nivelamento de dois meses, onde se trabalharam conteúdos de Matemática e Português. Ao seu término, os 280 estudantes com melhor rendimento integraram as classes do curso propriamente dito, distribuídos em quatro turmas.

Em 2003, foram inscritos 3.160 candidatos, e o formato foi alterado para expandir o público alvo. Dessa forma, foram selecionados os 530 alunos com melhor rendimento em testes de qualificação de Matemática e Português, e dispensou-se a etapa de nivelamento. Os alunos foram agrupados em seis turmas, sendo duas na UFRPE (à tarde) e quatro na UFPE (duas à tarde e duas à noite).

As aulas são ministradas de março a dezembro, quando é realizado o vestibular, e não são interrompidas por eventuais paralisações de atividades nas universidades (férias, greves). Incluem 4,5 horas semanais de cada uma das seguintes disciplinas: Biologia, Física, Química, Matemática e Português, perfazendo uma carga horária de 90 horas 
mensais. São incorporadas ainda ao curso as disciplinas complementares de História, Geografia e Espanhol, com 18 horas mensais. A carga horária total do curso atinge 108 horas mensais. Às turmas da tarde são ministradas seis aulas por dia, de 45 minutos cada. As turmas da noite têm quatro aulas de 45 minutos diários, e seis aulas de 30 minutos aos sábados à tarde. Exige-se a freqüência mínima de $75 \%$ nas aulas; caso sua abstenção supere este índice, o estudante é desligado do programa. Em virtude do limitado espaço disponível, não são permitidos alunos ouvintes, isto é, que não passaram pela seleção proposta.

O Programa é supervisionado por professores das duas universidades, e há um supervisor para cada área de conhecimento. Há um coordenador geral, cargo ocupado atualmente pelo Prof. Dr. Manoel Lemos, do Departamento de Matemática, Centro de Ciências Exatas e da Natureza, da UFPE. Cabe à coordenação o acompanhamento do programa, mantendo reuniões periódicas para discutir critérios de seleção de alunos e professores, número de vagas, captação e alocação de recursos, conteúdo programático e atividades complementares, em conjunto com professores supervisores de área, instrutores e representantes discentes. Os professores supervisores, especialistas em suas respectivas áreas, têm a responsabilidade de selecionar os instrutores, planejar o programa teórico, e acompanhar seu cumprimento, e participar de eventuais palestras.

Os professores-instrutores das disciplinas são estudantes regularmente matriculados nas licenciaturas da UFPE e UFRPE. Os critérios de seleção envolvem análise do currículo e histórico escolar, disponibilidade de tempo, envolvimento com atividades de ensino e desempenho em aulas expositivas. O instrutor selecionado deve dedicar no mínimo 12 horas semanais, a fim de ministrar aulas, preparar material didático (transparências, exercícios, etc.) e participar de reuniões. Os instrutores são contemplados com bolsas de incentivo, administradas pela Fundação de Apoio ao Desenvolvimento da UFPE (FADE), cujo valor em 2003 foi de $\mathrm{R} \$ 220,00$ (ca. U\$75,00). Também são selecionados monitores, seguindo critérios semelhantes, os quais disponibilizam horários para esclarecimentos e resolução de exercícios, sem recebimento de bolsaauxílio.

O Programa não cobra taxa de inscrição, material e mensalidade. Busca, ainda, a isenção completa ou parcial do pagamento da inscrição no vestibular, junto à Covest (Comissão de Processos Seletivos e Treinamentos), responsável pelo vestibular das universidades federais de Pernambuco; solicita ajuda de instituições particulares e o auxílio oriundo de recursos de projetos. 


\section{A experiência da equipe de Biologia}

Nossa experiência no projeto refere-se ao ensino de Biologia, ministrado a todos os alunos independentemente do curso pretendido. Atualmente, a equipe de Biologia é composta pelo Professor-supervisor (com título de Doutor em Biologia), e seus orientandos: seis professoresinstrutores e três monitores, todos estudantes de Licenciatura em Ciências Biológicas da UFPE ou UFRPE.

O conteúdo de Biologia é dividido em três blocos temáticos que abrangem o programa do ensino médio solicitado pelo vestibular. $\mathrm{O}$ assunto é trabalhado oralmente, utilizando quadro-negro, textos e transparências. Devido a limitações de tempo e recursos, não há aulas práticas ou uso de laboratórios, embora se almeje proporcionar um enfoque aplicado. Estimula-se, ainda, a abordagem de temas interdisciplinares como meio ambiente, saúde e sexualidade, os quais refletem necessidades imediatas da própria comunidade. Para este fim, são colocados à disposição textos sobre o avanço tecnológico e temas "polêmicos" da biologia, tais como organismos geneticamente modificados.

Após o cumprimento do programa teórico, realizam-se revisões, testes e vestibulares simulados para acompanhar a aprendizagem do aluno. Monitores e professores ficam à disposição para atender alunos e resolver exercícios em horários previamente estabelecidos. Para os candidatos às Licenciaturas em Ciências Biológicas da UFPE e da UFRPE, são ministradas, fora do horário de aulas, palestras sobre mercado de trabalho, perfil dos cursos e área de atuação do licenciado, e realizados seminários sobre pesquisas conduzidas na UFPE.

\section{RESULTADOS DO PROGRAMA}

Desde 1997, com a primeira turma do Programa Professores do Terceiro Milênio (PPTM), os resultados têm sido extremamente satisfatórios. Em primeiro lugar, o número de alunos beneficiados tem aumentado consideravelmente, ampliando o enfoque social do programa. Em 1997, 120 alunos iniciaram efetivamente o programa, sendo que em 2001 este número cresceu para 200 (Figura 1). Em 2002, 280 alunos integraram o projeto, enquanto em 2003, o aumento foi ainda maior: 530 estudantes foram beneficiados. 
Figura 1 - Número anual de candidatos que iniciam, concluem e desistem do Programa Professores do Terceiro Milênio e índice de aprovação nos vestibulares de licenciaturas em Ciências das universidades federais de Pernambuco

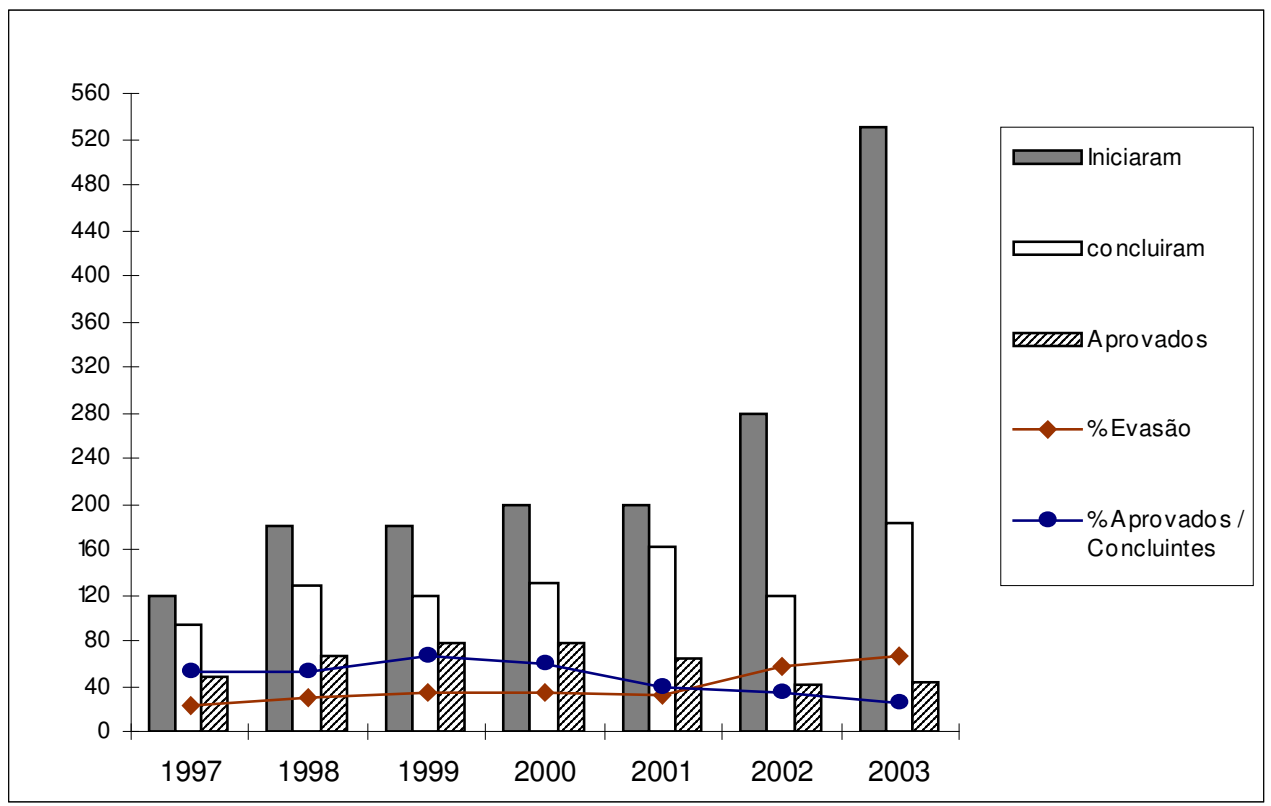

Com base no período de 1997 a 2001, observa-se que em média 70\% dos alunos efetivamente concluíram o curso. $\mathrm{O}$ índice de evasão, de cerca de 30\%, é alto e praticamente dobrou em 2002 e 2003: atingiu 57\% e 59\% respectivamente. Este índice tem causas diversas, como a falta de recursos para viabilizar o transporte e/ou a taxa de inscrição no vestibular (atualmente no valor de $\mathrm{R} \$ 90,00, c a$. U\$ 30,00), e ainda a necessidade de obter emprego imediatamente após conclusão do ensino médio.

Nem todos os que terminam o programa efetivamente se inscrevem no vestibular para as licenciaturas em Ciências das universidades federais de Pernambuco. Em 2001, por exemplo, dos 163 concluintes, apenas 122 fizeram vestibular para aqueles cursos. Por outro lado, em 2002 todos os 118 alunos que concluíram o programa realmente prestaram o referido vestibular. Em 2003, dos 220 alunos que concluíram o programa, 182 fizeram vestibular para as Licenciaturas em Ciências.

Em Pernambuco, o vestibular das universidades federais, aplicado pela COVEST, consta de uma primeira etapa com todas as disciplinas do 
curso médio e uma segunda com disciplinas específicas do curso desejado. Em 2001, 85,5\% dos alunos foram aprovados na $1^{a}$ fase; em 2002, 85,6\% e em 2003, 82,0\%. Esses índices elevados ilustram o potencial dos alunos do projeto. A aprovação final - após a 2a etapa - nas licenciaturas em Ciências das universidades federais nos últimos anos encontra-se na Figura 1.

Os índices gerais de aprovação nos vestibulares no período de 1997 a 2002 superaram as expectativas, variando de $41,0 \%$ a $66,0 \%$ (Figura 1). Neste intervalo, a média geral foi de $53,2 \%$, semelhante à observada em muitos cursos particulares de Recife. Em 2002, houve pequena queda no índice de aprovação de alunos. Em 2003, esta tendência de queda foi agravada: cerca de $25 \%$ dos concluintes conseguiram vaga nos cursos de Licenciatura em Ciências das universidades federais. Os dados sobre matrícula inicial, evasão e aprovação dos últimos sete anos estão combinados na Figura 1.

Em 2001, os egressos do programa ocuparam de $7 \%$ a $13 \%$ das vagas oferecidas nas licenciaturas das universidades federais de Pernambuco (Tabela 1). Além do ótimo índice de aprovação, alguns alunos tiveram excelente classificação, como o $1^{\circ}$ lugar da Licenciatura em Matemática da UFPE. Onze alunos foram aprovados em outros cursos, alguns dos quais altamente concorridos como Medicina Veterinária, Arquitetura e Jornalismo, demonstrando a competitividade dos estudantes do projeto.

Em 2002, apesar da queda no rendimento geral dos alunos do programa, a aprovação em Biologia pode ser considerada ótima: dos 38 candidatos, 15 foram aprovados (39,5\%). Vale destacar que, em 2002, os alunos do programa ocuparam 22,0\% das vagas oferecidas pela UFPE para a Licenciatura em Ciências Biológicas. Assim como nos anos anteriores, diversos egressos do programa passaram em cursos de bacharelado. Uma vez que, devido à natureza do programa, os alunos deveriam concorrer a uma das licenciaturas propostas, tais aprovações não foram contabilizadas.

Em 2003, houve, ainda, queda na aprovação em Ciências Biológicas: 14 candidatos $(23,7 \%)$ ingressaram naquelas licenciaturas. Deve-se destacar que o primeiro colocado no vestibular para Licenciatura em Ciências Biológicas da UFPE foi aluno do Programa. Desta forma, embora a taxa de aprovação tenha caído, o número absoluto de ex-alunos ingressando nas universidades federais de Licenciatura em Biologia foi praticamente mantido em relação a 2002. 
Tabela 1 - Distribuição dos alunos do Programa "Professores do Terceiro Milênio" aprovados no vestibular para as licenciaturas em Ciências da UFPE e UFRPE nos últimos três anos (2001 - 2003)

\begin{tabular}{|c|c|c|c|c|c|c|c|c|c|c|c|c|c|c|c|c|c|c|c|c|c|}
\hline \multirow{3}{*}{ LICENCIATURAS } & \multicolumn{6}{|c|}{ UFPE } & \multicolumn{6}{|c|}{ UFRPE } & \multicolumn{9}{|c|}{ TOTAL } \\
\hline & \multicolumn{2}{|c|}{2001} & \multicolumn{2}{|c|}{2002} & \multicolumn{2}{|c|}{2003} & \multicolumn{2}{|c|}{2001} & \multicolumn{2}{|c|}{2002} & \multicolumn{2}{|c|}{2003} & \multicolumn{2}{|c|}{2001} & \multicolumn{2}{|c|}{2002} & \multicolumn{2}{|c|}{2003} & \multicolumn{3}{|c|}{$\begin{array}{c}\% \text { DE APROVADOS/ } \\
\text { VAGAS }\end{array}$} \\
\hline & $\mathrm{NVO}$ & NAA & NVO & NAA & $\mathrm{NVO}$ & NAA & $\mathrm{NVO}$ & NAA & $\mathrm{NVO}$ & NAA & $\mathrm{NVO}$ & NAA & $\mathrm{NVO}$ & NAA & $\mathrm{NVO}$ & NAA & $\mathrm{NVO}$ & NAA & 2001 & 2002 & 2003 \\
\hline BIOLOGIA & 50 & 05 & 50 & 11 & 50 & 05 & 80 & 10 & 80 & 04 & 80 & 08 & 130 & 15 & 130 & 15 & 130 & 14 & 11,6 & 11,6 & 10,8 \\
\hline COMPUTAÇÃO & - & - & - & - & - & - & 30 & 02 & 30 & 0 & 30 & 02 & 30 & 02 & 30 & 0 & 30 & 02 & 07 & 0 & 7,0 \\
\hline FÍSICA & 30 & 06 & 30 & 03 & 30 & 01 & 80 & 08 & 80 & 06 & 80 & 07 & 110 & 14 & 110 & 09 & 110 & 08 & 13 & 8,2 & 7,3 \\
\hline MATEMÁTICA & 40 & 07 & 40 & 03 & 40 & 05 & 80 & 05 & 80 & 04 & 80 & 02 & 120 & 13 & 120 & 07 & 120 & 07 & 10,8 & 5,8 & 5,8 \\
\hline QUÍMICA & 30 & 06 & 30 & 01 & 30 & 04 & 80 & 05 & 80 & 09 & 80 & 08 & 110 & 11 & 110 & 10 & 110 & 13 & 10 & 9,1 & 11,8 \\
\hline TOTAL & 150 & 24 & 150 & 18 & 150 & 15 & 350 & 30 & 350 & 23 & 350 & 27 & 500 & 55 & 500 & 41 & 500 & 42 & 11,0 & 8,2 & 8,4 \\
\hline
\end{tabular}

(NVO) - Número de Vagas Oferecidas; (NAA) - Número de Alunos Aprovados. 
Quanto à conquista de vagas, as licenciaturas em Biologia foram os cursos mais procurados e que tiveram maior número de aprovados nos vestibulares de 2001 e 2002, em termos absolutos, sugerindo uma elevada procura (e um bom preparo) dos candidatos. Em 2002, 38 alunos concorreram às licenciaturas em Biologia, sendo aprovados 11 na UFPE e 4 na UFRPE. Em 2003, 59 alunos concorreram, sendo 14 aprovados. Isto reflete o avanço tecnológico e a popularização da Biologia nos últimos anos, estendendo-se para o terceiro milênio. Adicionalmente, em 2002 os alunos participaram de um ciclo de palestras sobre a atuação profissional do biólogo, a estrutura do curso, o mercado de trabalho, os desafios e as oportunidades gerados em um curso de licenciatura em Biologia. Tais palestras tiveram repercussão entre os alunos do Programa, estimulando a busca por este curso, e foram mantidas em 2003.

\section{DISCUSSÃO}

\section{A inclusão social através do acesso à universidade}

O Programa Professores do Terceiro Milênio vem, aos poucos, alcançando seu principal objetivo: preparar alunos oriundos de escolas públicas para enfrentar o desafio de concorrer a uma vaga de acesso à universidade. Com isso, espera-se reduzir diferenças na "competitividade" de alunos de escolas públicas e particulares no vestibular, ao mesmo tempo que complementa a formação dos conteúdos específicos e promove o contato de alunos tradicionalmente menos favorecidos com o universo acadêmico. A cada ano, tem se aumentado o número geral de vagas para atender à crescente procura dos interessados, confirmando a visibilidade e o impacto social alcançados. Em seis anos, o número de alunos beneficiados praticamente quintuplicou.

As perspectivas de aprovação dos alunos no vestibular são otimistas, não só pelo aumento de alunos participantes, mas também pela experiência adquirida e pelo reconhecimento da sociedade. Pode-se dizer que, atualmente, o Programa Professores do Terceiro Milênio está entre os maiores do Brasil em sua função, tanto pelo número de alunos atendidos, quanto pela quantidade de egressos de escola pública que ingressa em uma universidade federal. De 1997 a 2003, 420 alunos do Programa foram aprovados em cursos de licenciatura em Ciências da UFPE e UFRPE.

O Programa, evidentemente, age apenas como um paliativo dentro de um perverso contexto de desigualdade social. Neste sentido, Ortega argumenta que: 
“...se a escola pública de ensino médio não se preocupar com o acesso ao ensino superior, diante de uma exigência cada vez maior do conhecimento para obter um emprego,poderá estar colaborando para que seus alunos sejam excluídos, e os que já se sentem à margem poderão ver o ensino médio como etapa final da escolaridade e sentir falta de perspectivas de trabalho, sentir falta dos instrumentos necessários para o exercício da cidadania." (2001, p. 154)

Muitas escolas e cursos pré-vestibulares priorizam mecanismos de divulgação dos resultados - em jornais de grande circulação, através de "listões" e incontáveis primeiros lugares - ao invés de promover a socialização dos conteúdos pelo candidato. Trabalha-se com um mercantilismo, uma troca de valores, onde se paga por um serviço, desvinculando qualquer relação após o término do contrato. Para Soares, Alves e Oliveira (2001), isto funciona como um artifício das boas instituições para permanecerem no mercado, com prestígio e elevados valores nas mensalidades.

"A aprovação no vestibular de uma universidade bem conceituada tornou-se um desafio para a maioria dos estudantes do ensino médio e fonte de prestigio para as escolas. Todos os anos, tão logo os resultados dos principais vestibulares são divulgados, a mídia expõe peças publicitárias de cursinhos pré-vestibulares ou mesmo de escolas repletas de imagens de festas, jovens radiantes e muitas lágrimas de emoção. Essas campanhas têm como eixo o número ou a porcentagem de alunos aprovados e a quantidade de primeiros lugares... Por isto, as escolas, mesmo aquelas não associadas a cursinhos pré-vestibulares, capitalizam os resultados de seus egressos do ensino médio para a manutenção de seu prestígio acadêmico." (2001, p 71)

Existe, assim, um processo de "depuração" entre alunos das redes pública e privada, no qual o vestibular é o "golpe de misericórdia" (Castro, 2001, p.112). Segundo esse autor, trata-se da "limpeza social" mais vasta e radical que ocorre no ensino superior, não por culpa deste, mas dos níveis mais baixos que imprimem aos alunos velocidades distintas de avanço dentro do sistema, em razão do seu status de origem. Em recente trabalho, Whitaker e Fiamengue (2001) analisaram a aprovação de egressos de escolas públicas e particulares em universidades estaduais de São Paulo durante 10 anos, e confirmaram a primazia de ex-alunos da rede particular em cursos de elevada concorrência. A ocupação de vagas, em Direito e Medicina, por ex-alunos de escolas públicas por exemplo, foi de apenas $9,8 \%$ e $7,8 \%$, respectivamente.

As referidas autoras sugerem cautela ao se inferir que o estudo em escola particular automaticamente aumenta a chance de aprovação. 
Comumente, alunos da rede particular - em geral de maior poder aquisitivo - também freqüentam os famosos cursinhos preparatórios - estes sim, centros de preparação massiva para as provas vestibulares. Com a variedade de opções de formato, de matérias isoladas a simulados, passando por oficinas específicas, é natural que alunos expostos a tais cursos reconheçam padrões nos exames vestibulares e tenham maior probabilidade de sucesso.

Não se pode negar que a inclusão social implica o acesso a todos os níveis de educação, e igualdade de oportunidade em todos os níveis. Mas será que o ingresso em uma universidade pública de alto nível garante o sucesso profissional e a ascensão social de um ex-aluno da rede pública? Diversos autores destacam a ocupação de cursos mais "fáceis" pelos exalunos da escola pública. Castro (2001) afirma que os candidatos de nível socioeconômico muito baixo que conseguem passar no vestibular com notas que permitiriam freqüentar os cursos mais competitivos representam uma minoria. Ainda que alunos de baixa renda fossem aprovados em cursos "elitizados" como Medicina e Direito, tais cursos exigem dedicação integral, mais tempo para estudo e a realização de estágios intensivos, o que nem sempre é possível para um estudante que necessita trabalhar, além de aquisição de material e bibliografia dispendiosos.

\section{As Licenciaturas em Ciências como instrumentos de transformação}

Ao focalizar especificamente os cursos de Licenciatura em Ciências, o Programa contribui para repensar o valor desses cursos nas universidades em que estão inseridas. Como afirma Bazzo (2000),

"A falta de atratividade da profissão faz com que os potenciais alunos das licenciaturas ou da Pedagogia calculem muito bem a relação custo-benefício, quando vão escolher que curso fazer. O esforço despendido para passar no vestibular e permanecer num curso exigente e sério faz com que eles avaliem com o mesmo cuidado suas aptidões e o retorno profissional que terão. Não é por acaso que a evasão nas licenciaturas é altíssima em cursos como os de Matemática, Física, Quimica e Biologia." (p. 61)

Ao envolver alunos de Licenciatura em Ciências como instrutores, o Programa beneficia significativamente o próprio curso, oferecendo aos graduandos a oportunidade de um treinamento orientado, com diretrizes pedagógicas claras e profundo comprometimento social. Em parte por ser um curso noturno, há escassez de estágios e bolsas para estudantes das licenciaturas da UFPE, comparado aos cursos de bacharelado. Ao conviver 
diariamente com alunos do ensino médio, utilizando sua própria experiência como universitários, os licenciandos têm a oportunidade de conhecer melhor seu futuro público-alvo, aproximando-se da realidade educacional do país.

A função social do Programa Professores do Terceiro Milênio vai além da formação de conteúdos. No caso específico de Biologia, a equipe busca trabalhar conhecimentos para o vestibular e também o cotidiano do aluno, tais como temas de saúde, meio ambiente, qualidade de vida, sexualidade, entre outros. Isso destaca o compromisso dos licenciandos em ampliar a função de professor, colocando-o como educador engajado na conquista da cidadania de uma população tradicionalmente alijada de direitos básicos, como acesso à educação superior gratuita e de qualidade.

Segundo os Parâmetros Curriculares Nacionais, o ensino de Biologia deve abordar temas contemporâneos desenvolvidos pela pesquisa científica, com a finalidade de fortalecer as relações entre Ciências, Tecnologia e Sociedade. Ou seja, os desdobramentos da Biologia fazem também emergir aspectos éticos associados à produção e aplicação desses conhecimentos, que precisam sustentar uma discussão social (Mayer, Carneiro-Leão, Jófili, 2000). Nesse sentido, a Licenciatura em Ciências Biológicas da UFPE vem sofrendo mudanças em sua grade curricular para atender às exigências do novo perfil profissional, sintonizado com as necessidades do mercado e as exigências do MEC. Ao mesmo tempo, pretende-se formar um profissional com visão crítica dos problemas sociais, econômicos e políticos associados à realidade educacional brasileira. Por exemplo, disciplinas da área de humanas foram incorporadas com maior ênfase na estrutura curricular do curso.

Como ressalta Giovani (1998), a formação do professor precisa ser concebida como um processo de desenvolvimento que se inicia no momento da escolha profissional e ao longo da carreira, incluindo as oportunidades de novos cursos, projetos e programas de formação continuada. Com o intuito de qualificar jovens competentes e dar-lhes oportunidade o projeto Professores do Terceiro Milênio vai além da aprovação do aluno; deseja-se, do hoje aluno, amanhã professor, uma participação mais efetiva na sociedade, em sua comunidade. Acreditamos que o projeto ajuda a preparar cidadãos habilitados e qualificados para iniciarem as mudanças necessárias na educação e conseqüentemente na sociedade como um todo. 


\section{Problemas e Perspectivas}

O programa oferece um mecanismo diferenciado de incremento do acesso à universidade, sobre o qual não pesa o estigma de cotas reservadas. Tais fatores devem ser levados em consideração quando da definição de projetos de inclusão social. A universidade pública pode e deve ser utilizada como agente transformador, contribuindo para a redução das desigualdades de acesso universal à educação. O sistema de cotas (para exalunos de escolas públicas, por exemplo) é uma iniciativa bem intencionada e que pode promover a ascensão social dos beneficiados. Sua implementação per se já demonstra a ousadia dos administradores em reconhecer as desigualdades do sistema e investir em soluções rápidas. Entretanto, parece não ter havido suficiente consulta a todas as partes envolvidas - professores e alunos universitários, por exemplo, têm contribuído pouco neste debate. Decisões nesse sentido correm o risco de assumir uma postura paternalista, e questões de natureza jurídica ainda precisam ser esclarecidas. Algumas iniciativas chegaram até a ter efeito contrário: o primeiro autor deste trabalho cursou Agronomia na década de 80 ao lado de beneficiados pelo recurso conhecido como "Lei do Boi" (Lei $5.465 / 68)$, na UFRPE. Longe de beneficiar filhos de pequenos agricultores, a maioria dos beneficiados consistia de filhos de fazendeiros e usineiros locais, para os quais o acesso à educação e seus instrumentos era infinitamente maior, uma questão também levantada por César (2003).

Em projetos de "reforço" (um termo que desperta um certo preconceito por inerentemente considerar o candidato "fraco") mais duradouros, como o Programa Professores do Terceiro Milênio, os alunos conseguem a vaga exclusivamente por seus méritos, competindo através da mesma seleção com os demais candidatos. Há, evidentemente, aspectos que precisam ser aperfeiçoados. Por exemplo, o sucesso do programa seria ainda maior caso houvesse menor evasão. Desconhece-se o índice de aprovação dos alunos que deixam o projeto antes do seu término, especialmente quando se percebe que a falta de tempo e de recursos financeiros representa o principal obstáculo. Cada aluno precisa se deslocar diariamente até a universidade para assistir às aulas, e tem despesas com transporte, eventualmente alimentação e fotocópias. Sendo, em geral, alunos de baixa renda, um gasto aparentemente pequeno torna-se mais um fator a impulsionar a evasão e o desestímulo. $O$ ideal seria oferecer algum auxílio financeiro para os alunos do programa - inviável com os recursos atualmente recebidos. O custo com a inscrição no vestibular tem sido subsidiado. Em 2002, 90\% dos alunos foram beneficiados com isenção parcial ou total da taxa. 
Há outros problemas operacionais: falta agilidade no repasse das verbas, e o horário dos instrutores é periodicamente alterado, pois suas disciplinas na universidade estão irregulares em relação ao ano letivo "normal" devido às greves. Nem todos os problemas, naturalmente, são de natureza administrativa; muitos alunos freqüentam o programa com intenção de concorrer a outros cursos, apesar da orientação expressa para as licenciaturas. Com isso, ao se aproximar o vestibular, tais alunos são desligados do programa, aumentando os índices de evasão. Eles ocupam a vaga de um potencial candidato às licenciaturas.

O sucesso do programa é resultado do esforço conjunto de professores da UFPE e UFRPE, Diretoria Científica da FACEPE, Secretarias de Educação e Ciência e Tecnologia de Pernambuco, dos alunosinstrutores, monitores e alunos do programa. Apesar das ameaças de término por falta de verbas, espera-se manter o programa em 2004. Não se pode ignorar um programa que teve 6.180 (seis mil cento e oitenta!) candidatos inscritos para a turma de 2004. Pretende-se estabelecer a institucionalização pela UFPE, com o aproveitamento das horas aula como parte da prática de ensino obrigatória aos cursos de Licenciatura. A busca de novas parcerias - inclusive com instituições particulares - também está sendo considerada.

Os resultados até agora fortalecem a importância do programa como um instrumento capaz de favorecer uma parcela de estudantes economicamente menos favorecidos. Nossa intenção é de que o programa seja temporário. Isso porque, como educadores, acreditamos no dia em que não haverá a necessidade de se estabelecer cotas ou pré-vestibulares para qualquer categoria: numa sociedade democratizada, todos os cidadãos terão igualdade de condições para receber educação universitária gratuita e de qualidade.

\section{REFERÊNCIAS BIBLIOGRÁFICAS}

ANDRADE, D. R. et al. Prevest. Anais do I Encontro Brasileiro de Extensão Universitária, João Pessoa - PB, publicação em CD-ROM, 2002.

BAZZO, V. L. Para onde vão as Licenciaturas? A formação de professores e as políticas públicas. Revista "Educação", v. 25, n. 1, p. 53-65, 2000.

CASTRO, C. M. Educação Superior e Equidade: Inocente ou Culpada? Ensaio: Avaliação de Políticas Públicas em Educação, Rio de Janeiro, v. 9 n. 30, p. 109-122, 2001. 
CESAR, R. C. L. Ações afirmativas no Brasil: e agora, doutor? Ciência Hoje, Rio de Janeiro, v. 33, n. 195, p. 26-32, 2003.

GIOVANI, L. M. Do professor informante ao professor parceiro: reflexões sobre o papel da universidade para o desenvolvimento profissional de professores e as mudanças na escola. Cadernos CEDES, Campinas, n. 19, p.46-58, 1998.

INEP. Instituto Nacional de Estudos e Pesquisas Educacionais. Anísio Teixeira (2001). Censo Escolar. Disponível em <www.inep.gov.br Acessado em: 22/6/2003.

LARANJEIRA, M. I. et al. Referências para a Formação de professores. In: BICUDO, M. A. V.; SILVA JR., C. A. (org.). Formação do Educador e Avaliação Educacional, v. 2 Formação Inicial e Contínua, São Paulo: Unesp, p. 17-47, 1999.

MAYER, M.; CARNEIRO-LEÃO, A. M. A.; JÓFILI, Z. Os descompassos entre os PCNs e a formação de professores de Biologia. Anais do VII Encontro Perspectivas do Ensino de Biologia, São Paulo, p. 43-47, 2000.

ORTEGA, E. M. V. O ensino médio público e o acesso ao ensino superior. Estudos em Avaliação Educacional. São Paulo, Fundação Carlos Chagas, n. 23, p. 153-176, jan./jun. 2001.

PISA (2000) Measuring Student Knowledge and Skills. OEDC, Paris. Disponível em: <http:/ / pisa.oecd.org > Acessado em: 20 fev 2003.

SOARES, J. F.; ALVES, M. T. G.; OLIVEIRA, R. M. O efeito de 248 escolas de nível médio no vestibular da UFMG nos anos de 1998, 1999 e 2000. Estudos em Avaliação Educacional. São Paulo, Fundação Carlos Chagas, n. 24, p. 69-101, jul./dez. 2001.

VASCONCELOS, S. D. Reestruturação do Curso de Licenciatura em Ciências Biológicas da UFPE: o perfil do aluno. Anais do VII Encontro Perspectivas de Ensino de Biologia, São Paulo, p. 341-345, 2000.

WHITAKER, D. C. A.; FIAMENGUE, E. C. Ensino Médio: função do Estado ou da Empresa? Educação e Sociedade. Campinas, ano XXII, n.75, p.200-232, 2001.

Recebido em: março 2004 Aprovado para publicação em: abril 2004 